\title{
Incidence, cost and gender differences of oropharyngeal and noncervical anogenital cancers in South Korea
}

\author{
Inseon Choi ${ }^{1}$ Donghwan Lee ${ }^{2}$, Kyung-Bok Son ${ }^{1}$ and SeungJin Bae ${ }^{1 *}$ (D)
}

\begin{abstract}
Background: Human papillomavirus (HPV) is associated with a significant public health burden, yet few studies have been conducted in Asia, especially on noncervical cancers. We estimated the incidence and cost of oropharyngeal and noncervical anogenital (anal, vulvar, vaginal, penile) cancer in Korea.
\end{abstract}

Methods: We conducted a retrospective cohort study using Korea's National Health Insurance (NHI) claim database from 2013 to 2016. The main outcome measures were the number of respective cancer incidences during the study period and the annual costs per patient in the first year after diagnosis, which was adjusted by relevant variables based on the regression analysis.

Results: During the study period, 8022 patients with these cancers were identified, and oropharyngeal cancer comprised $46 \%$ of them. The crude incidence rate for male oropharyngeal cancer was significantly higher than that of females (3.1 vs. 0.7 per 100,000 as of 2016, respectively). Additionally, the crude incidence of male oropharyngeal cancer increased from 2.7 in 2013 to 3.1 in 2016, whereas that of female and other cancers was stable during the study period. The mean annual incidence-based cost per patient in 2016 was highest for oropharyngeal cancers ( 21,870 USD), and it was significantly higher in males than in females based on then regression analysis $(p<.001)$.

Conclusions: Oropharyngeal cancer comprises the highest number of HPV-associated noncervical cancer incidences in Korea, and the incidence and cost of oropharyngeal cancer was significantly higher among males than females. More aggressive public health policy toward males may decrease gender gap of oropharyngeal cancer.

Keywords: Cost, Incidence, Burden of disease, Oropharyngeal cancer, Noncervical anogenital cancer

\section{Introduction}

Cancer is a major cause of death in Korea, resulting in 82,155 deaths in 2018 [1]. Human papillomavirus (HPV) is attributable to $11.3 \%$ of cases and $6 \%$ of deaths of the infection-related cancers in Korea [2]. Currently, a 2valent $H P V$ vaccine $\left(\right.$ Cervarix $\left.^{\text {tix }}\right)$, 4-valent vaccine (Gardasil $^{\circ}$ ), and 9-valent vaccine (Gardasil ${ }^{\circ}$;) are available in Korea [3], and the National Immunization Program

\footnotetext{
* Correspondence: sjbae@ewha.ac.kr

${ }^{1}$ College of Pharmacy, Ewha Womans University, Seoul, South Korea

Full list of author information is available at the end of the article
}

(NIP) has been implemented for 12-year-old girls with 2-valent HPV vaccine and 4-valent vaccine since June 2016 [4]. A previous Korean study using claim data suggested that the number of patients with diseases associated with HPV steadily increased between 2002 and 2015 [5]. In addition, in 2015, a total of 124.9 million USD was spent in Korea for healthcare costs for HPVassociated diseases [5]. Previous studies reported that the prevalence of cervical cancer per 100,000 decreased from 114.0 in 2007 to 90.8 in 2011. However, the prevalence of noncervical HPV-associated cancers, such as

(c) The Author(s). 2020 Open Access This article is licensed under a Creative Commons Attribution 4.0 International License, which permits use, sharing, adaptation, distribution and reproduction in any medium or format, as long as you give appropriate credit to the original author(s) and the source, provide a link to the Creative Commons licence, and indicate if changes were made. The images or other third party material in this article are included in the article's Creative Commons licence, unless indicated otherwise in a credit line to the material. If material is not included in the article's Creative Commons licence and your intended use is not permitted by statutory regulation or exceeds the permitted use, you will need to obtain permission directly from the copyright holder. To view a copy of this licence, visit http://creativecommons.org/licenses/by/4.0/ The Creative Commons Public Domain Dedication waiver (http://creativecommons.org/publicdomain/zero/1.0/) applies to the data made available in this article, unless otherwise stated in a credit line to the data. 
anal (2.7 to 3.5), vulvar (1.6 to 1.7$)$, vaginal (1.4 to 1.5$)$, and penile (0.7 to 0.9$)$ cancers per 100,000 , tended to increase from 2007 to 2011 [6].

Most HPV-associated cancer studies in Korea have estimated prevalence-based cost $[5,6]$, yet studies on incidence-based healthcare costs are scarce. Prevalencebased costs estimate the total cost of a disease during a particular year, including survivors and end-of-life patients [7-9]. Incidence-based costs estimate the cost of treatment for patients first diagnosed in a particular year [7-9]. Since a prevalence-based approach captures the medical expenditure that occurs during a specific period regardless of the timing of the disease incidence, its implication in estimating the burden of disease is limited [10]. However, incidence-based costs include only newly diagnosed patients, so it is possible to estimate health care costs after initial disease diagnosis [11]. Therefore, incidence-based cost estimation results are especially important for cancers, where most cost occur in the first year of the diagnosis [12-16]. The purpose of our study is to estimate the incidence rate and incidence-based healthcare cost of noncervical anogenital cancer and oropharyngeal cancer in Korea using nationally representative data.

\section{Materials and methods \\ Database}

We used the Health Insurance Review and Assessment (HIRA) database, which contains National Health Insurance (NHI) claims data in South Korea. The HIRA claims data cover almost 50 million patients and include utilization information regarding healthcare services reimbursed by the NHI (such as diagnosis code, cost of treatment, demographic characteristics, and prescription information) $[17,18]$. The HIRA dataset includes $100 \%$ of Korean residents, with $97 \%$ covered by the NHI and $3 \%$ by the Medical Aid program, which is designed for the underprivileged [19].

Our study was approved by the Institutional Review Board of Ewha Womans University (IRB File No. 168-10).

\section{Study population}

Patients with primary or secondary diagnosis of [6] oropharyngeal (including base of tongue, tonsil), anal, vulvar, vaginal, and/or penile cancer between January 2011 and December 2017 based on the International Classification of Diseases (ICD) code were identified from the NHI claim database. The ICD 10th codes for each cancer are as follows: oropharynx with base of tongue and tonsil (C01, C09, C10), anus (C21), vulva (C51), vagina (C52), and penis (C60).

The washout period was defined as two years based on the clinicians' advice that each patient could be defined as a new patient if there was no medical use for the same disease in the past two years based on the index date, which is the first diagnosed with corresponding cancers, from 2013 to 2016. Namely, to identify newly diagnosed patients, we excluded patients who had visited the medical institution with the same disease diagnosis during the two-year washout period (pre-index period). The follow-up period was defined as 1 year from the index date to estimate the annual cost per patient. The flow chart for the new patient included in the study through this operational definition is shown in Fig. 1. The Charlson comorbidity index (CCI) was used to adjust the comorbidities of patients [20].

\section{Outcomes}

We estimated the number of newly diagnosed patients and incidence rates from 2013 until 2016 with 2011 and 2012 being used for the washout period, and analyzed the incidence-based medical cost per patient per year of oropharyngeal (including base of tongue, tonsil) and anogenital cancer (vulvar, vaginal, penile, anal cancer). We calculated the crude incidence rate per 100,000 people using the entire Korean population for the corresponding year as a denominator for new patients. The age-standardized incidence rate (ASR) per 100,000 people was calculated based on the World Health Organization (WHO)'s 2000-2025 world standard population [21].

We calculated the direct medical cost from the Korean health care system perspective, which includes payer's cost and patients' cost sharing. Since Korean NHI has fee-for service system for most of the services except seven diseases areas (which are reimbursed by the Diagnosis Related Group), we estimated annual medical cost per patient by incorporating individual claim corresponds to each patient, including outpatient visits, laboratory tests, hospitalizations, and prescription medications [19] occurred within one-year following the index date. We estimated all costs by index year (2013-16). Because the diseases considered in this paper are rare, we included all patients in cost estimation. In order to summarize results less distorted by the outliers, we present the median of the cost estimates as well as the average.

All costs were adjusted by the medical care component of the Consumer Price Index in 2016 [22]. The cost was converted from Korean Won to US Dollar using the 20132016 average exchange rate $(1 \mathrm{USD}=1110 \mathrm{KRW})$ [23].

\section{Statistical analysis}

Descriptive statistics were used to examine the overall distribution of the new patients for each cancer. To compare the medical cost differences between groups of independent variables, parametric tests ( $t$-test, ANOVA test) and nonparametric tests (Wilcoxon test, KruskalWallis test) were performed. Regression analysis was 


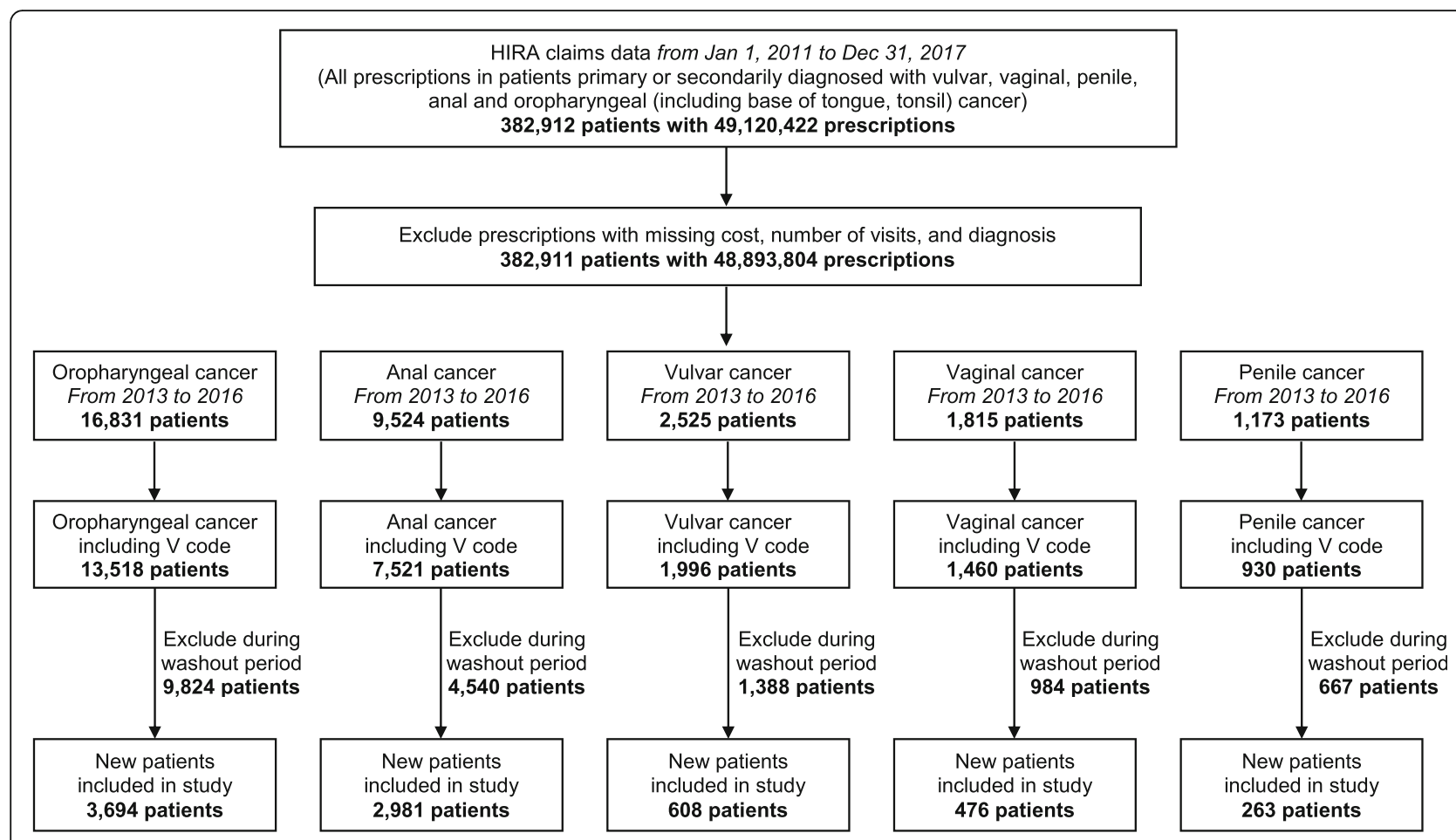

Fig. 1 Flow chart of new patients included in the study through operational definition. Flow chart of extracting new patients from 2013 to 2016 through operational definition using HIRA claims data from patients diagnosed primary or secondary with vulvar, vaginal, penile, anal and oropharyngeal (including base of tongue, tonsil) cancer from Jan 1, 2011 to Dec 31, 2017

used to identify the association of medical costs with the independent variables. Independent variables included sex $($ female $=0$, male $=1)$, age (under 65 or $65=0,65$ over $=$ 1 ), surgical experience (inexperience $=0$, experience $=1$ ), health plan type (healthcare insurance $=0$, Medicaid $=1$ ), year and CCI. The surgical experience variable indicates whether or not the patient has undergone surgery during the follow-up period. Since disease severity information is not available at the NHI claim database, surgical experience was employed to adjust for the patients' disease severity [24]. Because the distribution of medical costs was right-skewed, the log-transformation was considered [25, 26]. However, despite the conversion to the logarithm, Kolmogorov-Smirnov tests for checking normality failed for all cancer types $(p<0.05)$. Therefore, in addition to the linear regression model, generalized linear models (GLMs) were performed when the distribution of medical costs was assumed to be from gamma distribution. Gamma GLM fits a skewed distribution well and is frequently used for dealing with nonnormal data such as healthcare costs [27]. Using GLM, medical costs were analyzed by adjusting the effects of confounding factors such as age, surgical experience, health plan type, year, and CCI. Before adjusting for confounding factors, univariate analyses for each variable were also applied. After the analysis, regression models were compared based on the Akaike information criterion (AIC).
All data collection and statistical analysis were performed using SAS software (version 9.4, SAS Institute Inc., Cary, NC, USA) and RStudio (version 1.1.463, RStudio, Inc., USA). All analyses were conducted using $p<0.05$ as the level of significance.

\section{Results}

During the study period, 8022 new patients were identified, and the total number of patients with any of the five cancers increased from 1952 in 2013 to 2101 in 2016. Oropharyngeal cancer comprised $46 \%$ of them, followed by anal cancer (37\%). The demographic characteristics of newly diagnosed patients for oropharyngeal cancer and anogenital cancers are presented in Table 1. For all five cancers, the mean age was greater than 60 , and the CCI score was between 1 and 2. Most patients were covered by the NHI insurance $(>90 \%)$. There was a large gender gap in oropharyngeal cancer, with male patients comprising $81.2 \%$ (811 out of 999 patients) in 2016.

Table 2 shows the crude and age standardized incidence rates of each cancers from 2012 to 2016. In general, although the crude incidence rates slightly increased during the study period, the trend disappeared when age standardized rates were used. During the study period, consistently higher number of male patients were observed in oropharyngeal cancer, with crude incidence 
Table 1 Demographic characteristics of new patients for oropharyngeal and anogenital cancer, 2013-2016

\begin{tabular}{|c|c|c|c|c|}
\hline Variable & 2013 & 2014 & 2015 & 2016 \\
\hline \multicolumn{5}{|c|}{ 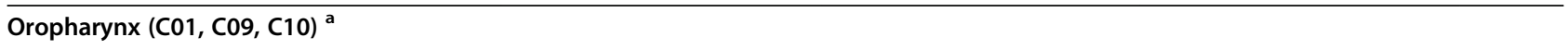 } \\
\hline $\mathbf{N}$ & 884 & 888 & 923 & 999 \\
\hline \multicolumn{5}{|l|}{ Gender, n (\%) } \\
\hline Male & $698(79.0)$ & $730(82.2)$ & $737(79.8)$ & $811(81.2)$ \\
\hline Female & $186(21.0)$ & $158(17.8)$ & $186(20.2)$ & $188(18.8)$ \\
\hline Age, mean (SD) & $61.2(12.2)$ & $61.6(12.5)$ & $62.0(12.5)$ & $61.9(12.5)$ \\
\hline CCI score, mean (SD) & $1.7(1.3)$ & $1.7(1.2)$ & $1.7(1.2)$ & $1.8(1.2)$ \\
\hline \multicolumn{5}{|l|}{ Health plan type, $\mathrm{n}(\%)$} \\
\hline Healthcare insurance & $824(93.2)$ & $839(94.5)$ & $868(94.0)$ & $927(92.8)$ \\
\hline Medicaid, etc. ${ }^{\text {b }}$ & $60(6.8)$ & $49(5.5)$ & $55(6.0)$ & $72(7.2)$ \\
\hline \multicolumn{5}{|l|}{ Anus (C21) } \\
\hline $\mathbf{N}$ & 758 & 702 & 762 & 759 \\
\hline \multicolumn{5}{|l|}{ Gender, n (\%) } \\
\hline Male & $388(51.2)$ & $404(57.5)$ & $425(55.8)$ & $376(49.5)$ \\
\hline Female & $370(48.8)$ & $298(42.5)$ & $337(44.2)$ & $383(50.5)$ \\
\hline Age, mean (SD) & $65.0(12.9)$ & $64.3(13.5)$ & $65.0(13.8)$ & $66.1(13.3)$ \\
\hline CCI score, mean (SD) & $2.0(1.1)$ & $1.9(1.2)$ & $2.0(1.2)$ & $1.9(1.2)$ \\
\hline \multicolumn{5}{|l|}{ Health plan type, n (\%) } \\
\hline Healthcare insurance & $704(92.9)$ & $652(92.9)$ & $688(90.3)$ & $688(90.7)$ \\
\hline Medicaid, etc. ${ }^{b}$ & $54(7.1)$ & $50(7.1)$ & $74(9.7)$ & $71(9.3)$ \\
\hline \multicolumn{5}{|l|}{ Vulva (C51) } \\
\hline $\mathbf{N}$ & 147 & 156 & 156 & 149 \\
\hline Age, mean (SD) & $62.0(17.0)$ & $58.7(16.0)$ & $64.3(16.0)$ & $64.0(15.0)$ \\
\hline CCI score, mean (SD) & $1.2(1.2)$ & $1.2(1.2)$ & $1.1(1.2)$ & $1.3(1.2)$ \\
\hline \multicolumn{5}{|l|}{ Health plan type, n (\%) } \\
\hline Healthcare insurance & $143(97.3)$ & $150(96.2)$ & $142(91.0)$ & $134(90.0)$ \\
\hline Medicaid, etc. ${ }^{\text {b }}$ & $4(2.7)$ & $6(3.8)$ & $14(9.0)$ & $15(10.0)$ \\
\hline \multicolumn{5}{|l|}{ Vagina (C52) } \\
\hline $\mathbf{N}$ & 102 & 115 & 136 & 123 \\
\hline Age, mean (SD) & $62.9(13.5)$ & $60.7(14.3)$ & $61.5(14.3)$ & $61.8(14.6)$ \\
\hline CCI score, mean (SD) & $1.5(1.2)$ & $1.7(1.2)$ & $1.4(1.2)$ & $1.5(1.3)$ \\
\hline \multicolumn{5}{|l|}{ Health plan type, $\mathrm{n}(\%)$} \\
\hline Healthcare insurance & $96(94.1)$ & $105(91.3)$ & $127(93.4)$ & $112(91.1)$ \\
\hline Medicaid, etc. ${ }^{b}$ & $6(5.9)$ & $10(8.7)$ & $9(6.6)$ & $11(8.9)$ \\
\hline \multicolumn{5}{|l|}{ Penis (C60) } \\
\hline $\mathbf{N}$ & 61 & 58 & 73 & 71 \\
\hline Age, mean (SD) & $63.7(16.0)$ & $65.5(15.4)$ & $68.5(12.6)$ & $66.7(14.8)$ \\
\hline CCl score, mean (SD) & $1.3(1.2)$ & $1.1(1.2)$ & $1.4(1.1)$ & $1.1(1.1)$ \\
\hline \multicolumn{5}{|l|}{ Health plan type, n (\%) } \\
\hline Healthcare insurance & $58(95.1)$ & $56(96.5)$ & $70(95.9)$ & $64(90.1)$ \\
\hline Medicaid, etc. ${ }^{b}$ & $3(4.9)$ & $2(3.5)$ & $3(4.1)$ & $7(9.9)$ \\
\hline
\end{tabular}

CCI Charlson Comorbidity Index, SD standard deviation

${ }^{a}$ Oropharyngeal cancer, including the base of tongue and tonsil

${ }^{\mathrm{b}}$ War veteran 
Table 2 Crude incidence rate (CR) and age-standardized incidence rate (ASR) of oropharyngeal and anogenital cancer

\begin{tabular}{|c|c|c|c|c|c|}
\hline \multirow[t]{2}{*}{ Cancer } & \multirow[t]{2}{*}{ Year } & \multicolumn{2}{|l|}{ Male } & \multicolumn{2}{|c|}{ Female } \\
\hline & & $\overline{C{ }^{b}}$ & $\overline{\operatorname{ASR}^{c}}$ & $\overline{C R^{b}}$ & $\overline{\operatorname{ASR}^{c}}$ \\
\hline \multirow{4}{*}{$\begin{array}{l}\text { Oropharynx } \\
(C 01,09,10)^{a}\end{array}$} & 2013 & 2.7 & 2.1 & 0.7 & 0.5 \\
\hline & 2014 & 2.9 & 2.1 & 0.6 & 0.4 \\
\hline & 2015 & 2.9 & 2.0 & 0.7 & 0.5 \\
\hline & 2016 & 3.1 & 2.2 & 0.7 & 0.5 \\
\hline \multirow{4}{*}{$\begin{array}{l}\text { Anus } \\
(\mathrm{C} 21)\end{array}$} & 2013 & 1.5 & 1.2 & 1.5 & 0.9 \\
\hline & 2014 & 1.6 & 1.2 & 1.2 & 0.7 \\
\hline & 2015 & 1.7 & 1.3 & 1.3 & 0.8 \\
\hline & 2016 & 1.5 & 1.0 & 1.5 & 0.9 \\
\hline \multirow{4}{*}{$\begin{array}{l}\text { Vulva } \\
\text { (C51) }\end{array}$} & 2013 & - & - & 0.6 & 0.4 \\
\hline & 2014 & - & - & 0.6 & 0.4 \\
\hline & 2015 & - & - & 0.6 & 0.4 \\
\hline & 2016 & - & - & 0.6 & 0.4 \\
\hline \multirow{4}{*}{$\begin{array}{l}\text { Vagina } \\
\text { (C52) }\end{array}$} & 2013 & - & - & 0.4 & 0.3 \\
\hline & 2014 & - & - & 0.4 & 0.3 \\
\hline & 2015 & - & - & 0.5 & 0.5 \\
\hline & 2016 & - & - & 0.5 & 0.3 \\
\hline \multirow{4}{*}{$\begin{array}{l}\text { Penis } \\
\text { (C60) }\end{array}$} & 2013 & 0.2 & 0.2 & - & - \\
\hline & 2014 & 0.2 & 0.2 & - & - \\
\hline & 2015 & 0.3 & 0.2 & - & - \\
\hline & 2016 & 0.3 & 0.2 & - & - \\
\hline
\end{tabular}

${ }^{a}$ Oropharyngeal cancer, including the base of tongue and tonsil

${ }^{\mathrm{b}}$ Crude incidence rate is calculated per 100,000 persons

c Age-standardized incidence rate is calculated per 100,000 persons; The age standardization method was a direct method and was adjusted to the World Standard Population of $2000-2025$ by WHO

rates per 100,000 for males vs. females being 3.1 vs. 0.7 in 2016, respectively (Table 2). Additionally, the crude incidence per 100,000 males increased from 2.7 in 2013 to 3.1 in 2016, but the incidence per 100,000 females did not change (0.7). A consistent pattern was seen in the age-standardized incidence rate, with the agestandardized incidence rates per 100,000 for males vs. females being 2.2 vs. 0.5 in 2016, respectively (Table 2). On the other hand, similar incidence rates for males and females were observed in anal cancer, and agestandardized incidence rates also showed consistent trend. For males, the crude incidence rate per 100,000 was highest for oropharyngeal cancer (3.1), followed by anal cancer (1.5) and penal cancer (0.3) in 2016. For females, the crude incidence rate per 100,000 was highest for anal cancer (1.5), followed by oropharyngeal cancer (0.7), vulvar cancer (0.6) and vaginal cancer (0.5) in 2016.

The total incidence-based medical cost for oropharyngeal and noncervical anogenital cancer in 20132016 was 133,964,586 USD, bringing a significant economic burden to Korea, and greatly increased from 27,803,613 USD in 2013 to 38,864,428 USD in 2016. Table 3 and Fig. 2 show the incidence-based cost per patient for oropharyngeal cancer and anogenital cancer (anal, vulvar, vaginal, penile cancer). The incidence-based cost per patient was highest in oropharyngeal cancer and lowest in penile cancer. In all five cancers, the incidence-based cost per patient increased between 2013 and 2016. Among them, vaginal cancer showed the steepest increase from USD 12,515 in 2013 to USD 18,636 in 2016, followed by anal cancer, which increased from USD 10,662 in 2013 to USD 15, 911 in 2016. The cost of oropharyngeal cancer was consistently higher for males than for females throughout the study period (Table 3, Fig. 2b). Specifically, the cost of oropharyngeal cancer per male patient was 23,041 USD whereas that per female being 16,819 USD in 2016. Accordingly, we analyzed cost per patient according to gender in oropharyngeal cancer through t-test and Wilcoxon test. The results demonstrated that the $p$-value of $<.001$ was significantly higher in male medical cost per patient than in females (Table 4).

Table 3 Incidence-based medical cost per patient of oropharyngeal and anogenital cancer in South Korea, 2013-2016

\begin{tabular}{|c|c|c|c|c|c|c|c|c|}
\hline \multirow[t]{2}{*}{ Cancer } & \multicolumn{2}{|l|}{2013} & \multicolumn{2}{|l|}{2014} & \multicolumn{2}{|l|}{2015} & \multicolumn{2}{|l|}{2016} \\
\hline & Mean (USD) & Median (USD) & Mean (USD) & Median (USD) & Mean (USD) & Median (USD) & Mean (USD) & Median (USD) \\
\hline Oropharynx $(C 01,09,10)^{a}$ & 18,867 & 17,874 & 21,624 & 20,111 & 21,668 & 20,408 & 21,870 & 20,759 \\
\hline Male & 19,719 & 18,445 & 22,418 & 20,635 & 22,828 & 21,492 & 23,041 & 21,606 \\
\hline Female & 15,671 & 13,294 & 17,955 & 17,075 & 17,071 & 15,116 & 16,819 & 13,857 \\
\hline Anus (C21) & 10,662 & 8195 & 12,630 & 10,105 & 13,737 & 9025 & 15,911 & 12,230 \\
\hline Male & 10,331 & 7301 & 13,088 & 10,105 & 13,226 & 8645 & 15,419 & 11,042 \\
\hline Female & 11,009 & 9379 & 12,008 & 10,115 & 14,382 & 9864 & 16,394 & 12,880 \\
\hline Vulva (C51) & 9176 & 6188 & 10,261 & 7075 & 13,056 & 8869 & 12,957 & 8032 \\
\hline Vagina (C52) & 12,515 & 9835 & 14,113 & 10,608 & 16,580 & 13,758 & 18,636 & 13,954 \\
\hline Penis (C60) & 6852 & 3409 & 8137 & 4114 & 10,601 & 4961 & 10,097 & 5512 \\
\hline
\end{tabular}

Unit: US dollar

Adjusted by the medical care component of the Consumer Price Index in 2016

a Oropharyngeal cancer, including the base of tongue and tonsil 
(a) Anal, oropharyngeal, penile, vaginal and vulvar cancer

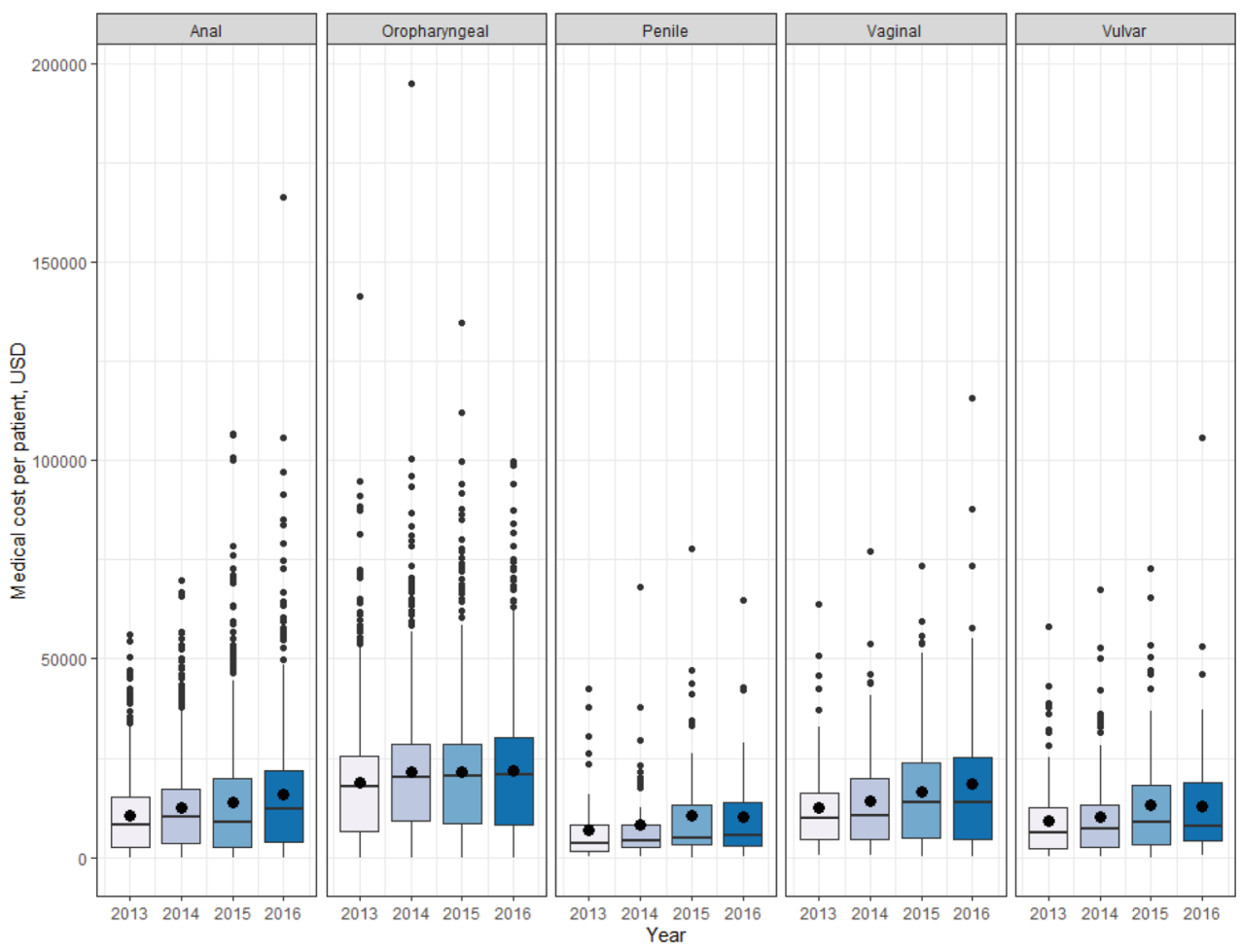

(b) Anal and oropharyngeal cancer by gender

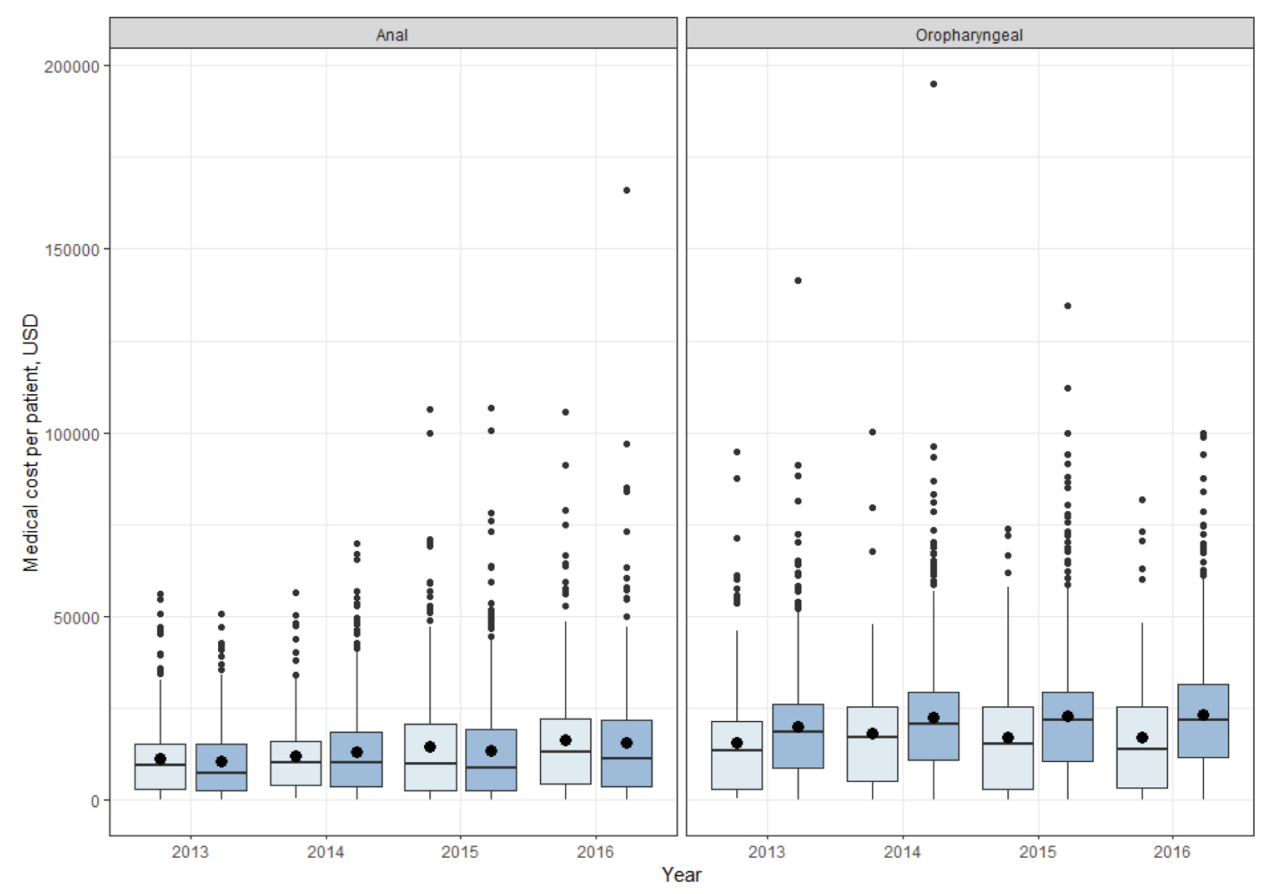

SEX 户 female 官 male

Fig. 2 (See legend on next page.) 
(See figure on previous page.)

Fig. 2 Incidence-based medical cost per patient, 2013-2016. a Anal, oropharyngeal, penile, vaginal and vulvar cancer. Incidence-based medical cost per patient in 2013-2016 of anal, oropharyngeal (including base of tongue, tonsil), penile, vaginal and vulvar cancer. All costs were adjusted by the medical care component of the Consumer Price Index in 2016. For the first year after diagnosis, the incidence-based cost per patient was highest in oropharyngeal cancer and lowest in penile cancer. In all five cancers, the incidence-based cost per patient increased between 2013 and 2016. b Anal and oropharyngeal cancer by gender. Differences in incidence-based medical cost per patient of anal cancer and oropharyngeal cancer according to gender. Oropharyngeal cancer demonstrated consistently higher results for males than for females during 2013-2016 for medical cost per patient. Anal cancer did not differ significantly between genders

Regression analysis was performed on oropharyngeal cancer and anal cancer, which can occur in both females and males. Table 4 shows the distribution of medical costs for each category of independent variable, and the regression analysis results are shown in Table 5. In multivariate regression analysis, the cost of oropharyngeal cancer was significantly higher in males than in females after adjustment for confounding factors such as age, year, surgery, health plan type, and CCI $(p<.001)$. Both the linear regression model and generalized linear model showed similar results. Also, the linear regression model showed better suitability as a result of comparing the goodnessof-fit of two multivariate models using the AIC.

Table 4 Distribution of medical costs of independent variables

\begin{tabular}{|c|c|c|c|c|c|c|c|c|}
\hline \multirow[t]{2}{*}{ Variable } & \multicolumn{4}{|c|}{ Oropharynx $(C 01,09,10)^{a}$} & \multicolumn{4}{|c|}{ Anus (C21) } \\
\hline & Mean & $p^{*}$ & Median & $p^{*}$ & Mean & $p^{*}$ & Median & $p^{*}$ \\
\hline \multicolumn{9}{|l|}{ Sex } \\
\hline Female & 16,837 & $<.001^{c}$ & 15,422 & $<.001^{d}$ & 13,528 & $0.295^{c}$ & 10,387 & $0.045^{d}$ \\
\hline Male & 22,056 & & 20,475 & & 13,003 & & 9196 & \\
\hline \multicolumn{9}{|l|}{ Age } \\
\hline$\leq 65$ & 22,195 & $<.001^{\mathrm{c}}$ & 20,644 & $<.001^{d}$ & 14,933 & $<.001^{\mathrm{c}}$ & 10,978 & $<.001^{d}$ \\
\hline$>65$ & 19,192 & & 17,087 & & 11,654 & & 8710 & \\
\hline \multicolumn{9}{|l|}{ Year } \\
\hline 2013 & 18,867 & $0.001^{\mathrm{e}}$ & 17,874 & $<.001^{f}$ & 10,662 & $<.001^{\mathrm{e}}$ & 8195 & $<.001^{f}$ \\
\hline 2014 & 21,624 & & 20,111 & & 12,630 & & 10,105 & \\
\hline 2015 & 21,668 & & 20,408 & & 13,737 & & 9025 & \\
\hline 2016 & 21,870 & & 20,759 & & 15,911 & & 12,230 & \\
\hline \multicolumn{9}{|l|}{ Surgery } \\
\hline Inexperience & 12,243 & $<.001^{\mathrm{c}}$ & 10,840 & $<.001^{\mathrm{d}}$ & 7490 & $<.001^{\mathrm{c}}$ & 3735 & $<.001^{\mathrm{d}}$ \\
\hline Experience & 24,011 & & 22,210 & & 16,216 & & 12,744 & \\
\hline \multicolumn{9}{|l|}{ Health plan type } \\
\hline Healthcare insurance & 21,045 & $0.960^{c}$ & 19,762 & $0.348^{d}$ & 13,120 & $0.131^{c}$ & 9777 & $0.222^{d}$ \\
\hline Medicaid, etc. ${ }^{\text {b }}$ & 20,990 & & 18,106 & & 14,655 & & 10,399 & \\
\hline \multicolumn{9}{|l|}{$\mathrm{CCl}$} \\
\hline 0 & 22,718 & $<.001^{\mathrm{e}}$ & 21,535 & $<.001^{f}$ & 15,040 & $<.001^{\mathrm{e}}$ & 12,418 & $<.001^{\mathrm{f}}$ \\
\hline 1 & 23,993 & & 22,091 & & 15,101 & & 12,154 & \\
\hline 2 & 18,567 & & 16,604 & & 11,303 & & 7729 & \\
\hline 3 & 20,095 & & 18,470 & & 13,158 & & 8781 & \\
\hline
\end{tabular}

Unit: US dollar

$\mathrm{CCl}$ Charlson Comorbidity Index

* $p<0.05$

a Oropharyngeal cancer, including the base of tongue and tonsil

${ }^{b}$ War veteran

${ }^{c} p$-value estimated by t-test

d $p$-value estimated by Wilcoxon test

e $p$-value estimated by ANOVA test

${ }^{f} p$-value estimated by Kruskal-Wallis test 
Table 5 Linear regression model and generalized linear model for incidence-based medical cost

\begin{tabular}{|c|c|c|c|c|c|c|c|c|c|}
\hline \multirow[t]{3}{*}{ Model } & \multirow[t]{3}{*}{ Variable } & \multicolumn{4}{|c|}{ Univariate } & \multicolumn{4}{|c|}{ Multivariate } \\
\hline & & \multicolumn{2}{|l|}{$\overline{\text { Anal }}$} & \multicolumn{2}{|c|}{ Oropharynx $^{a}$} & \multicolumn{2}{|l|}{$\overline{\text { Anal }}$} & \multicolumn{2}{|c|}{ Oropharynx ${ }^{a}$} \\
\hline & & $\beta$ & $p^{*}$ & $\beta$ & $p^{*}$ & $\beta$ & $p^{*}$ & $\beta$ & $p^{*}$ \\
\hline \multirow[t]{7}{*}{ Linear Regression Model } & Sex $($ ref $=$ female $)$ & -0.104 & 0.024 & 0.483 & $<.001$ & -0.150 & 0.004 & 0.422 & $<.001$ \\
\hline & Age $(r e f=\leq 65)$ & -0.180 & $<.001$ & -0.255 & $<.001$ & -0.136 & 0.001 & -0.185 & $<.001$ \\
\hline & Year & 0.102 & $<.001$ & 0.053 & 0.002 & 0.101 & $<.001$ & 0.046 & 0.003 \\
\hline & Surgery (ref = inexperience) & 1.040 & $<.001$ & 1.001 & $<.001$ & 1.037 & $<.001$ & 0.956 & $<.001$ \\
\hline & Health plan type (ref = healthcare insurance) & 0.113 & 0.174 & -0.118 & 0.131 & 0.115 & 0.131 & -0.121 & 0.091 \\
\hline & $\mathrm{CCl}$ & -0.065 & 0.001 & -0.079 & $<.001$ & 0.003 & 0.987 & -0.045 & 0.002 \\
\hline & AIC & & & & & \multicolumn{2}{|c|}{95,597} & \multicolumn{2}{|c|}{12,2571} \\
\hline \multirow[t]{7}{*}{ Generalized Linear Model } & Sex $(r e f=$ female $)$ & -0.040 & 0.286 & 0.270 & $<.001$ & -0.088 & 0.012 & 0.249 & $<.001$ \\
\hline & Age $(r e f=\leq 65)$ & -0.248 & $<.001$ & -0.145 & $<.001$ & -0.120 & $<.001$ & -0.118 & $<.001$ \\
\hline & Year & 0.129 & $<.001$ & 0.043 & 0.001 & 0.130 & $<.001$ & 0.038 & 0.002 \\
\hline & Surgery (ref = inexperience) & 0.773 & $<.001$ & 0.674 & $<.001$ & 0.759 & $<.001$ & 0.657 & $<.001$ \\
\hline & Health plan type (ref $=$ healthcare insurance) & 0.111 & 0.098 & -0.003 & 0.965 & 0.129 & 0.040 & 0.013 & 0.823 \\
\hline & $\mathrm{CCl}$ & -0.050 & 0.001 & -0.052 & $<.001$ & -0.009 & 0.534 & -0.034 & 0.003 \\
\hline & AlC & & & & & \multicolumn{2}{|c|}{103,891} & \multicolumn{2}{|c|}{132,144} \\
\hline
\end{tabular}

AIC Akaike Information Criterion, CCI, Charlson Comorbidity Index

${ }^{*} \mathrm{p}<0.05$

a Oropharyngeal cancer, including the base of tongue and tonsil

\section{Discussion}

Our study estimated the incidence and cost of oropharyngeal cancer (including base of tongue, tonsil) and anogenital cancer (anal, vulvar, vaginal, penile cancer) in 2013-2016 using nationally representative sample in Korea. During the study period, 8022 new patients were identified, and the total number of patients with five cancers increased from 1952 in 2013 to 2101 in 2016. The crude incidence rate for male oropharyngeal cancer was the highest among the five cancers, and oropharyngeal cancer showed a significant gender gap, with males vs. females being 3.1 vs. 0.7 per 100,000 as of 2016 , respectively. A similar pattern was seen in the agestandardized incidence rate, with males vs. females being 2.2 vs. 0.5 per 100,000 as of 2016, respectively. A previous Korean study also showed that the number of male patients was higher than that of female patients, which is similar to our study [5]. Additionally, the crude incidence of oropharyngeal cancer per 100,000 males increased from 2.7 in 2013 to 3.1 in 2016, whereas that of female and other cancers was stable during the study period. The incidence rate of oropharyngeal cancer associated with HPV is increasing in Asian countries such as Singapore, Taiwan and developed countries such as Northern Europe, Australia, and the United States, and the incidence rate is $2-3$ times higher in males than in females [28-31], which is consistent with our study.

Vaginal cancer and anal cancer demonstrated the steepest increase in medical costs during 2013-2016 (12,515 USD in 2013 to 18,636 USD in 2016 (49\%); 10,662 USD in 2013 to 15,911 USD in 2016 (49\%), respectively). The cost of oropharyngeal cancer was the highest among the five cancers, which is consistent with a previous study [32]. Oropharyngeal cancer is anatomically complex and difficult to operate compared to other cancers, and reconstruction may be added to restore function [33]. Therefore, the cost of surgery is expected to be higher than that of other cancers. Additionally, Targeted anticancer drug cetuximab has been reimbursed since 2014, which is in line with a sudden increase in expenditure in 2014, whereas only existing chemotherapy is reimbursed for the rest of the other cancers [34]. Moreover, because the head and neck are the organs that are used for speaking and swallowing food, it is closely related with patients' quality of life, and there is a risk of having a disability even after treatment such as neck resection [35]. Therefore, aggressive prevention of oropharyngeal cancer should be considered to improve health outcomes as well as reduce financial burden. Regression analysis was conducted in oropharyngeal cancer and anal cancer to estimate gender-specific annual cost, since those two cancers can occur in both genders. The cost of oropharyngeal cancer for males was significantly higher than that of females based on the regression analysis $(p<.001)$, both in univariate and multivariate analysis. Higher cost for males was also found in previous studies [5, 36]. An American study found that female head and neck cancer patients did not receive active treatment compared to male counterpart [36]. In addition, a Korean study analyzed the medical costs of 
HPV-related diseases in 2015, and reported that the proportion of males using radiation therapy and operation was higher than that of females [5]. Also, given that smoking is closely related with oropharyngeal cancer and smoking prevalence for males is higher than that of females, smoking might be related our finding [37-39]. Thus, under-treatment of female patients, along with high smoking prevalence of males, might be attributable to the gender difference. Future study which includes smoking variable is needed.

It is not surprising that annual costs were significantly higher as years pass and for the patient with higher disease severity (defined based on surgery experience). Interestingly, our analysis showed that patients under 65 and a lower CCI had significantly higher cost based on the multivariate analysis, using both the GLM and OLS models. Since we defined cancer patients based on primary or secondary diagnosis only, patients who are defined to have respective cancers based on the tertiary or beyond diagnoses codes are not included in our analysis. Since those patients are likely to be older and have higher CCI scores, our study might underestimate the cost of patients with higher CCI or older age; thus, our study should be interpreted with caution.

A previous prevalence-based cost-of-illness study estimated the health care costs of HPV-associated diseases in Korea using claims data in 2015 and suggested that the number of patients for anal, vulvar, vaginal and penile cancer was $2071,588,383$, and less than 300 , respectively [5]. Since we estimated the new patients of each cancer, our estimates are lower than the prevalence of each cancer, yet the trend observed in their study is consistent with what we have estimated in the number of incidences of each cancer. Since our definition of oropharyngeal cancer $(\mathrm{C} 01, \mathrm{C} 09, \mathrm{C} 10)$ is broader than that of the previous study (C10), caution should be taken when making comparison between the two studies. The prevalence-based healthcare costs per patient in a previous study were estimated at 4096 USD for oropharyngeal, 3737 USD for vaginal, 3370 USD for vulvar, 2807 USD for anal and 2169 USD for penile in 2015. The cost of oropharyngeal cancer was the highest, and the cost of penile cancer was the lowest, which is consistent with our study. The prevalence-based cost estimated in a previous study and the incidence-based cost estimated in our study are nearly five times different. This difference appears to be due to the high initial treatment cost of cancer after the first diagnosis $[12,13,15,16]$. As such, the cost of incidence and prevalence-based cost are quite different and should not be confused.

The HPV associated annual cost per patient in 2016 was estimated to be 14,536 USD for vaginal cancer, 14, 002 USD for anal cancer, 6736 USD for oropharyngeal cancer, 5049 USD for penile cancer and 3226 USD for vulvar cancer, respectively, after accounting for the HPV attributable fraction [28]. Overseas countries estimated the incidence rate and medical cost of $\mathrm{HPV}$-associated noncervical cancers. A Danish study estimated the crude annual incidence rate of HPV-associated anogenital cancers (anal, penile, vaginal, vulvar cancer) in Denmark in 2004-2007 and suggested that the crude incidence rates for anal, penile, vaginal and vulvar cancer were 1.9, 1.7, 0.9 and 3.6 per 100,000 persons, respectively [15], which was higher than what we observed in our study $(1.5,0.3$, 0.5, 0.6 for each year 2016, respectively) [15]. According to another Danish study, the incidence of anal cancer in Denmark has been steadily increasing, presumably due to patterns of change in sexual behavior [40]. The sex culture of Korea has changed rapidly in recent years, and the trend of an open sex culture is spreading due to the rapid westernization of social culture, which explains our increasing trend [41]. Therefore, appropriate prevention should be considered to prevent the increase in the incidence rate of HPV-associated disease in Korea. The incidence of oropharyngeal disease was estimated in Singapore, and the crude incidence per 100,000 persons of oropharyngeal squamous cell carcinoma was 2.66 for males and 0.72 for females in 2008-2012, which translates into 2.44 for males and 0.44 for females for the ASR per 100,000 [30]. Given that our ASR per 100,000 were 2.1 for males and 0.4 for females, our finding is a little bit lower than that of the Singaporean study. The Singaporean study suggested that Singapore has a potential burden of male oropharyngeal cancer and that changing current HPV precautions that focus on cervical cancer may also help prevent male oropharyngeal cancer. The American study calculated incidence-based medical costs for HPV-associated disease in 2004-2007 and reported that the annual direct medical costs per case was highest for the oropharyngeal cancer $(43,200$ USD) and lowest for the penile cancer being the lowest $(19,800$ USD) [42], which is consistent with our study. In terms of the absolute value, our values are relatively low in all disease areas. The United States mainly employs private health insurance and the charges for service are relatively high $[43,44]$ whereas Korea has national health insurance and the fee for medical services in Korea is around $60-80 \%$ of the original price [45]. Therefore, it is not surprising that our medical cost estimates in terms of the absolute value are relatively low compared with those of the American study.

Our study has some limitations. The cost of disease may be underestimated because non-medical costs, such as transportation costs, caregiver costs, and productivity losses are excluded. Second, we defined patients based on the primary or secondary diagnosis, so disease recorded after secondary diagnosis was excluded. Therefore, the result of estimating medical costs may vary 
according to such operational definition. Although large data sets are used, the CCI used in the regression analysis may depend on these operational definitions. Third, The HIRA database does not provide information on smoking status, tumor stage, or HPV status. Considering that smoking can exacerbate the progression of cancer, it is a limitation of our study. We included the surgery variable in the regression model to adjust for the disease severity, and assumed that experiencing surgery indicated higher cancer severity, which is a clear limitation. In addition, we could not tell whether the cancer patients are having primary cancer or metastasis, based on the NHI claim database. Since patients with metastatic cancer receive different treatment methods than those diagnosed with non-metastatic cancer, the cost can be different. Last, future studies reporting recurrence costs are needed.

However, our study has the following strengths. HIRA claim database contains comprehensive health care utilization information for almost 50 million Koreans, which provide an optimal environment to conduct a population-based study for rare diseases. In addition, 99\% of HIRA claims data are claimed through electronic data interchange (EDI) [18]. Therefore, it is expected that almost all patients who used medical services for oropharyngeal and anogenital cancer (anal, vulvar, vaginal, penile cancer) during 2013-2016 would be included [46].

To our knowledge, our study is the first to estimate the incidence-based medical cost for oropharyngeal (including base of tongue, tonsil) and anogenital cancer (anal, vulvar, vaginal, penile cancer) in Asia. It is also the first to show that the incidence-based medical costs of oropharyngeal and anal, vulvar, vaginal, and penile cancers are increasing in Korea. The incidence-based medical cost estimation results in our study are particularly useful when considering disease prevention and can be useful as a basis for providing estimates of the potential costs $[47,48]$.

\section{Conclusion}

The incidence-based cost per patient of oropharyngeal cancer (including the base of tongue, tonsil) and anogenital cancer (anal, vulvar, vaginal, penile cancer) increased from 2013 to 2016. Specifically, the incidence of oropharyngeal cancer was significantly higher in men, and costs were significantly higher in men than in women. More aggressive public health policy toward males may decrease the gender gap of oropharyngeal cancer.

\section{Acknowledgements}

Not applicable.

\section{Authors' contributions}

IC conducted the data collection, statistical analysis and interpretation. IC and SB designed the analysis and generated the manuscript. SB, DL and KB interpreted and supervised the statistical analysis of the data. All authors critically edited the manuscript and approved the final version.

\section{Funding}

This work was financially supported by Merck Sharp \& Dohme, Seoul, South Korea [grant number M20197901]. The funding body has not been involved with the study design nor the conduct of the study.

\section{Availability of data and materials}

The data that support the findings of this study are available from [Health Insurance Review and Assessment Service] but restrictions apply to the availability of these data, which were used under license for the current study, and so are not publicly available. Data are however available from the authors upon reasonable request and with permission of [Health Insurance Review and Assessment Service].

Ethics approval and consent to participate

Our study was approved by the Institutional Review Board of Ewha Womans University (IRB File No. 168-10).

Consent for publication

Not applicable.

\section{Competing interests}

Authors were financially supported by MSD Korea.

\section{Author details}

${ }^{1}$ College of Pharmacy, Ewha Womans University, Seoul, South Korea. ${ }^{2}$ Department of Statistics, Ewha Womans University, Seoul, South Korea.

Received: 9 February 2020 Accepted: 22 June 2020

Published online: 29 June 2020

\section{References}

1. Jung K-W, Won Y-J, Kong H-J, Lee ES. Prediction of cancer incidence and mortality in Korea, 2018. Cancer Res Treat. 2018;50(2):317.

2. Shin A, Park S, Shin H, Park E-H, Park SK, Oh J-K, Lim M-K, Choi BY, Boniol M, Boffetta P. Population attributable fraction of infection-related cancers in Korea. Ann Oncol. 2010;22(6):1435-42.

3. Kim Y-T, Serrano B, Lee J-K, Lee H, Lee S-W, Freeman C, Oh J-K, Alemany L, Bosch F-X, Bruni L. Burden of human papillomavirus (HPV)-related disease and potential impact of HPV vaccines in the Republic of Korea. Papillomavirus Res. 2019;7:26-42.

4. KCDC: (Korea Centers for Disease Control and Prevention). Epidemiology and management of infectious diseases targeted for vaccination (5th edition). Chapter 20 Human Papilloma Virus 2017.

5. Ki M, Choi HY, Han M, Oh J-K. The economic burden of human papillomavirus infection-associated diseases in the Republic of Korea, 20022015. Vaccine. 2018:36(31):4633-40.

6. Kim $Y$ et al. Economic analysis of humanpapilloma virus (HPV) vaccine. National Evidence-based healthcare Collaborating Agency, Research Report. Seoul. 2012;1.1:1-277.

7. Byford S, Torgerson DJ, Raftery J. Cost of illness studies. Bmj. 2000;320(7245): 1335

8. Rice D. Cost-of-illness studies: fact or fiction? Lancet. 1994;344(8936):151920.

9. Segel JE. Cost-of-illness studies-a primer. RTI-UNC Center of Excellence in Health Promotion Economics; 2006. p. 1-39.

10. Koopmanschap MA. Cost-of-illness studies. Pharmacoeconomics. 1998;14(2): 143-8.

11. Barlow WE. Overview of methods to estimate the medical costs of cancer. Med Care. 2009:47(7 Suppl 1):S33.

12. Abramowitz L, Saint Guily JL, Moyal-Barracco M, Bergeron C, Borne H, Dahlab A, Bresse X, Uhart M, Cancalon C, Catella L. Epidemiological and economic burden of potentially HPV-related cancers in France. PLoS One. 2018;13(9):e0202564.

13. Hylin $\mathrm{H}$, Thrane $\mathrm{H}$, Pedersen $\mathrm{K}$, Kristiansen IS, Burger EA. The healthcare costs of treating human papillomavirus-related cancers in Norway. BMC Cancer. 2019:19(1):426.

14. Lairson DR, Wu C-F, Chan W, Dahlstrom KR, Tam S, Sturgis EM. Medical care cost of oropharyngeal cancer among Texas patients. Cancer Epidemiol Prev Biomarkers. 2017;26(9):1443-9. 
15. Olsen J, Jørgensen TR, Kofoed K, Larsen HK. Incidence and cost of anal, penile, vaginal and vulvar cancer in Denmark. BMC Public Health. 2012;12(1): 1082.

16. Shin J-Y, Kim SY, Lee K-S, Lee S-I, Ko Y, Choi Y-S, Seo HG, Lee J-H, Park J-H Costs during the first five years following cancer diagnosis in Korea. Asian Pac J Cancer Prev. 2012;13(8):3767-72.

17. Cheol Seong S, Kim Y-Y, Khang Y-H, Heon Park J, Kang H-J, Lee H, Do C-H, Song J-S, Hyon Bang J, Ha S. Data resource profile: the national health information database of the National Health Insurance Service in South Korea. Int J Epidemiol. 2016;46(3):799-800.

18. Kim J, Yoon S, Kim L-Y, Kim D-S. Towards actualizing the value potential of Korea health insurance review and assessment (HIRA) data as a resource for health research: strengths, limitations, applications, and strategies for optimal use of HIRA data. J Korean Med Sci. 2017;32(5):718-28.

19. Aljunid SM, Srithamrongsawat S, Chen W, Bae SJ, Pwu R-F, Ikeda S, Xu L. Health-care data collecting, sharing, and using in Thailand, China mainland, South Korea, Taiwan, Japan, and Malaysia. Value Health. 2012;15(1):S132-8.

20. Charlson ME, Pompei P, Ales KL, MacKenzie CR. A new method of classifying prognostic comorbidity in longitudinal studies: development and validation. J Chronic Dis. 1987;40(5):373-83.

21. Ahmad OB, Boschi-Pinto C, Lopez AD, Murray CJ, Lozano R, Inoue M: Age standardization of rates: a new WHO standard. Geneva: World Health Organization 2001, 9(10)..

22. Statistics Korea, Korean Statistical Information Service. consumer price index [http://kosis.kr/statHtml/statHtml.do?orgld=101\&tblld=DT_1J17001\&vw_cd= MT_ZTITLE\&list_id=C1_15\&seqNo=\&lang_mode=ko\&language $=$ kor\&obj_ var_id=\&itm_id=\&conn_path=MT_ZTITLE (Accessed 2 Sept 2019)].

23. Bank of Korea. Economic Statistics System [http://ecos.bok.or.kr/ (Accessed 2 Sept 2019)].

24. Woo HK, Park JH, Kang HS, Kim SY, Lee SI, Nam HH. Charlson comorbidity index as a predictor of long-term survival after surgery for breast cancer: a nationwide retrospective cohort study in South Korea. J Breast Cancer. 2010; 13(4):409-17.

25. Briggs A, Gray A. The distribution of health care costs and their statistical analysis for economic evaluation. J Health Services Research Policy. 1998; 3(4):233-45.

26. Mihaylova B, Briggs A, O'Hagan A, Thompson SG. Review of statistical methods for analysing healthcare resources and costs. Health Econ. 2011; 20(8):897-916.

27. Lindsey JK, Jones B. Choosing among generalized linear models applied to medical data. Stat Med. 1998;17(1):59-68.

28. de Martel C, Plummer M, Vignat J, Franceschi S. Worldwide burden of cancer attributable to HPV by site, country and HPV type. Int J Cancer. 2017; 141(4):664-70

29. Hwang TZ, Hsiao JR, Tsai CR, Chang JS. Incidence trends of human papillomavirus-related head and neck cancer in Taiwan, 1995-2009. Int J Cancer. 2015;137(2):395-408.

30. Lam JO, Lim W-Y, Chow K-Y, D'Souza G. Incidence, trends and ethnic differences of oropharyngeal, anal and cervical cancers: Singapore, 19682012. PLoS One. 2015;10(12):e0146185.

31. Pytynia KB, Dahlstrom KR, Sturgis EM. Epidemiology of HPV-associated oropharyngeal cancer. Oral Oncol. 2014;50(5):380-6.

32. Massa ST, Osazuwa-Peters N, Boakye EA, Walker RJ, Ward GM. Comparison of the financial burden of survivors of head and neck cancer with other cancer survivors. JAMA Otolaryngol Head Neck Surg. 2019:145(3):239-49.

33. National Cancer Information Center, HPV related oropharyngeal cancer [https://www.cancer.go.kr/lay1/program/S1T211C223/cancer/view. do?cancer_seq=8723939\&menu_seq=20527071 (Accessed 27 Dec 2019)].

34. Health Insurance Review and Assessment Service, Specialized in notification such as chemotherapy, 2019.9 [http://www.hira.or.kr/rd/ anticancer/antiCancerList.do?pgmid=HIRAA030023030000 (Accessed 27 December 2019)].

35. Taylor JC, Terrell JE, Ronis DL, Fowler KE, Bishop C, Lambert MT, Myers LL, Duffy SA. Disability in patients with head and neck cancer. Archives of Otolaryngology-Head \& Neck Surgery. 2004;130(6):764-9.

36. Park A, Albaster A, Shen H, Mell LK, Katzel JA. Are women with head and neck cancer undertreated?. Am Soc Clin Oncol. 2018:LBA6002.

37. Ministry of Health \& Welfare and Korea Centers for Disease Control and Prevention. Korea National Health and Nutrition Examination Survey 2013 (KNHANES VI) [https://knhanes.cdc.go.kr/knhanes (Accessed 05 May 2020)].
38. Anantharaman D, Muller DC, Lagiou P, Ahrens W, Holcátová I, Merletti F, Kjærheim K, Polesel J, Simonato L, Canova C. Combined effects of smoking and HPV16 in oropharyngeal cancer. Int J Epidemiol. 2016;45(3):752-61.

39. Mashberg A, Boffetta P, Winkelman R, Garfinkel L. Tobacco smoking, alcohol drinking, and cancer of the oral cavity and oropharynx among US veterans. Cancer. 1993;72(4):1369-75.

40. Nielsen A, Munk C, Kjaer SK. Trends in incidence of anal cancer and highgrade anal intraepithelial neoplasia in Denmark, 1978-2008. Int J Cancer. 2012;130(5):1168-73.

41. Lee IS, Choi GY, Cha SH, Park HY, Lee JJ. A survey on the sexual behavior of adolescents in South Korea: The third survey in 2007. Korean J Obstet Gynecol. 2010;53(6):512-19.

42. Chesson HW, Ekwueme DU, Saraiya M, Watson M, Lowy DR, Markowitz LE. Estimates of the annual direct medical costs of the prevention and treatment of disease associated with human papillomavirus in the United States. Vaccine. 2012;30(42):6016-9.

43. DeNavas-Walt, Carmen. Income, poverty, and health insurance coverage in the United States (2005), Current Population Reports. Washington, D.C.: US Census Bureau. U.S. Government Printing Office; 2006:60-231.

44. Jung Y. American healthcare reform and implications. International Labor Brief. 2008;65:20-35.

45. Choi DZ. Future perspective of the government's policy to enhance health insurance coverage. Establishing a new coverage-enhancing policy satisfying both the public and the physician. Public Health Affairs. 2018;2(1): 9-15

46. Nam-Kyong C. Public health- and social pharmacy-related study using the Korean Health Insurance Review and Assessment Service (HIRA) claims data. Korean Academy Managed Care Pharmacy. 2015;4(1):42-9.

47. Kim Y, Shin S, Park J, Jung Y, Kim J, Lee T. Costing methods in healthcare. National Evidence-based healthcare Collaborating Agency, Research Report, NECA Research Method Series, Seoul, Korea; 2013:1-181.

48. Tarricone R. Cost-of-illness analysis: what room in health economics? Health policy. 2006;77(1):51-63.

\section{Publisher's Note}

Springer Nature remains neutral with regard to jurisdictional claims in published maps and institutional affiliations.

Ready to submit your research? Choose BMC and benefit from:

- fast, convenient online submission

- thorough peer review by experienced researchers in your field

- rapid publication on acceptance

- support for research data, including large and complex data types

- gold Open Access which fosters wider collaboration and increased citations

- maximum visibility for your research: over $100 \mathrm{M}$ website views per year

At $\mathrm{BMC}$, research is always in progress.

Learn more biomedcentral.com/submissions 